\title{
Methoxide of An Anderson-Type Polyoxometalate And Its Conversion to A New Type of Species, $\left[\mathrm{IMo}_{9} \mathrm{O}_{32}(\mathrm{OH})\left(\mathrm{OH}_{2}\right)_{3}\right]^{4-}$
}

\author{
Daisuke Honda, Tomoji Ozeki, ${ }^{*}$ and Atsushi Yagasaki* \\ Department of Chemistry, Kwansei Gakuin University, Sanda 669-1337, Japan, and Department of \\ Chemistry and Materials Science, Tokyo Institute of Technology, Tokyo 152-8551, Japan
}

\section{Supporting Information}

Figure S1. IR spectra of $\mathbf{1}$ (top) and $\mathrm{TBA}_{4}\left[\mathrm{IMo}_{9} \mathrm{O}_{32}(\mathrm{OH})\left(\mathrm{OH}_{2}\right)_{3}\right] \cdot \mathrm{H}_{2} \mathrm{O}$ (bottom).

Figure S2. IR spectra of $\mathrm{TBA}_{3}\left[\mathrm{IMo}_{6} \mathrm{O}_{22}(\mathrm{OMe})_{2}\right]$ in Nujol mull (top) and in $\mathrm{MeCN}$ (bottom).

Figure S3. IR spectra of $\mathrm{TBA}_{3}\left[\mathrm{IMo}_{6} \mathrm{O}_{22}(\mathrm{OMe})_{2}\right]$ in wet $\mathrm{MeCN}$.

Figure S4. IR spectra of $\mathrm{TBA}_{4}\left[\mathrm{IMo}_{9} \mathrm{O}_{32}(\mathrm{OH})\left(\mathrm{OH}_{2}\right)_{3}\right] \cdot \mathrm{H}_{2} \mathrm{O}$ in $\mathrm{MeCN}$.

Figure S5. IR spectra of $\mathrm{TBA}_{4}\left[\mathrm{IMo} \mathrm{O}_{32}(\mathrm{OH})\left(\mathrm{OH}_{2}\right)_{3}\right] \cdot \mathrm{H}_{2} \mathrm{O}$ in wet $\mathrm{MeCN}$.

Figure S6. IR spectra of $\mathrm{TBA}_{6}\left[\left(\mathrm{IMo}_{7} \mathrm{O}_{26}\right)_{2}\right]$ in Nujol mull (top) and in $\mathrm{MeCN}$ (bottom). 
Figure S1. IR spectra of 1 (top) and $\mathrm{TBA}_{4}\left[\mathrm{IMo}_{9} \mathrm{O}_{32}(\mathrm{OH})\left(\mathrm{OH}_{2}\right)_{3}\right] . \mathrm{H}_{2} \mathrm{O}$ (bottom).

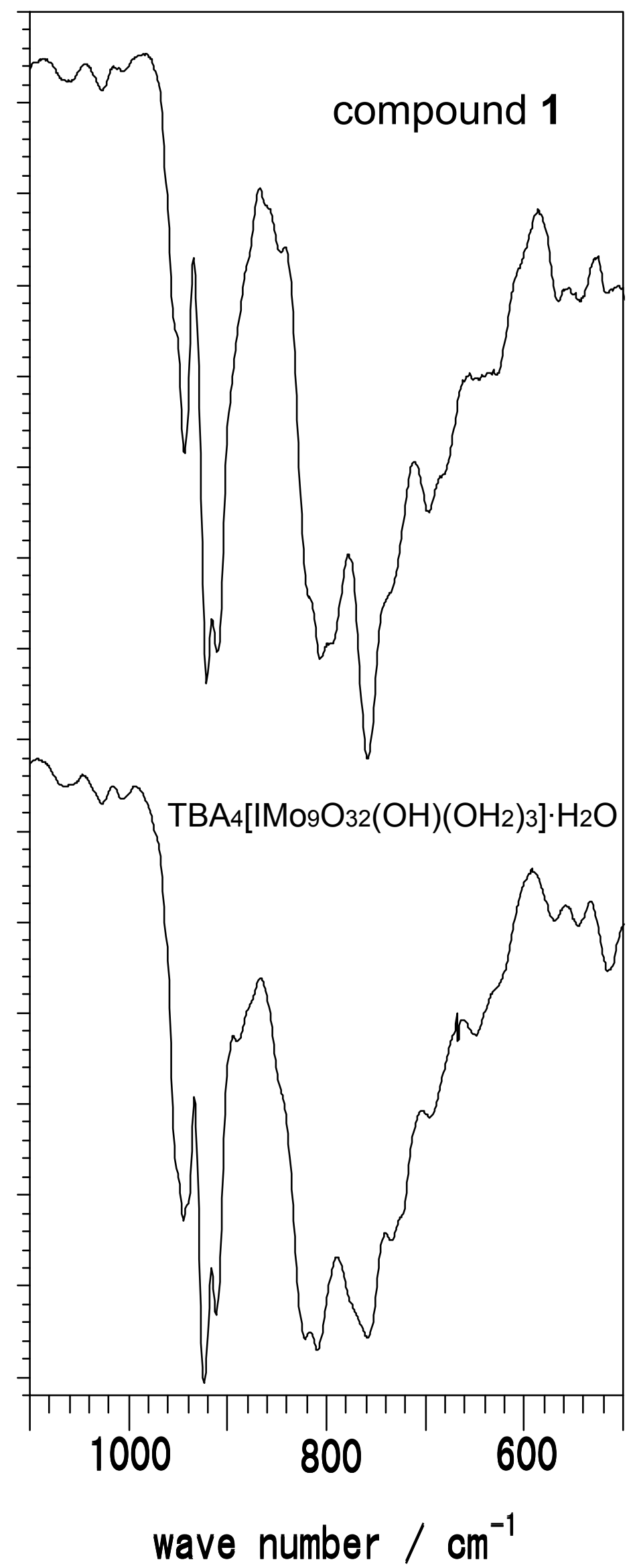


Figure S2. IR spectra of $\mathrm{TBA}_{3}\left[\mathrm{IMo}_{6} \mathrm{O}_{22}(\mathrm{OMe})_{2}\right]$ in Nujol mull (top) and in $\mathrm{MeCN}$ (bottom).

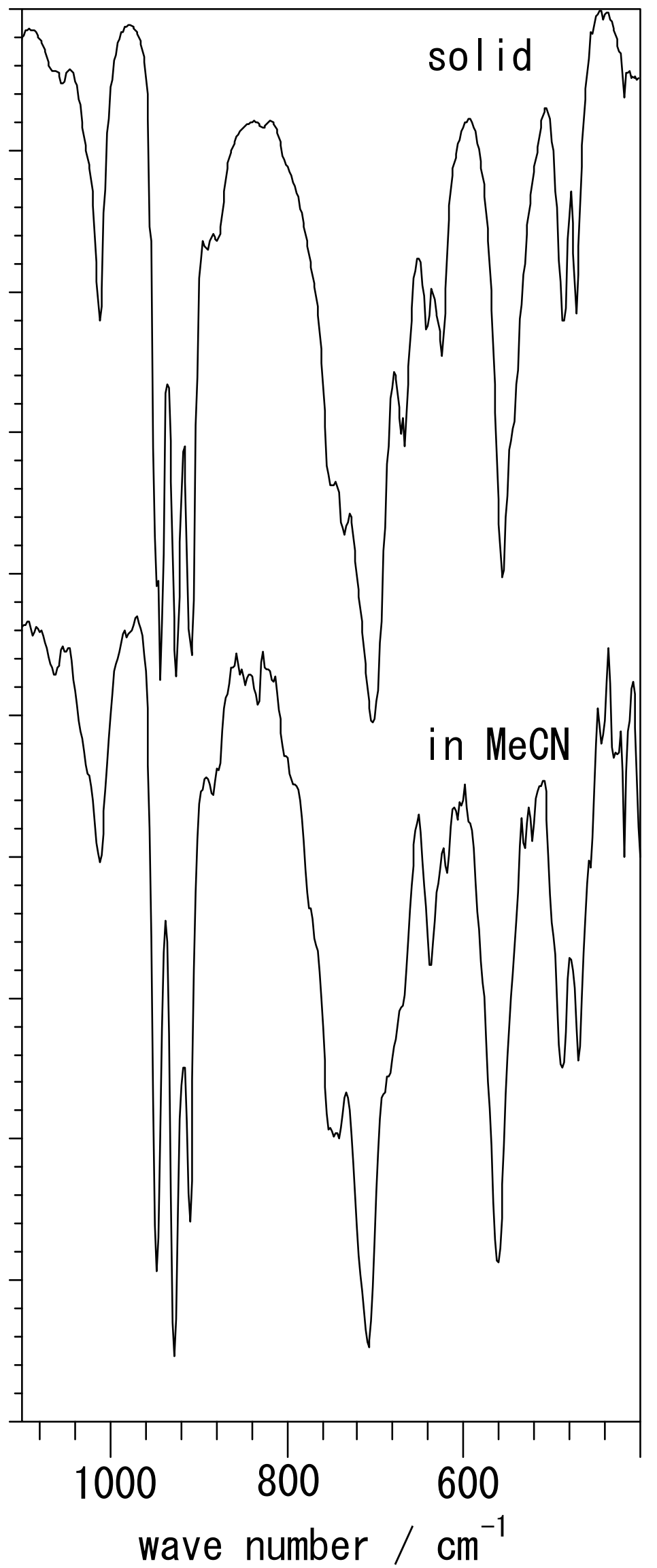


Figure S3. IR spectra of $\mathrm{TBA}_{3}\left[\mathrm{IMo}_{6} \mathrm{O}_{22}(\mathrm{OMe})_{2}\right]$ in wet $\mathrm{MeCN}$.

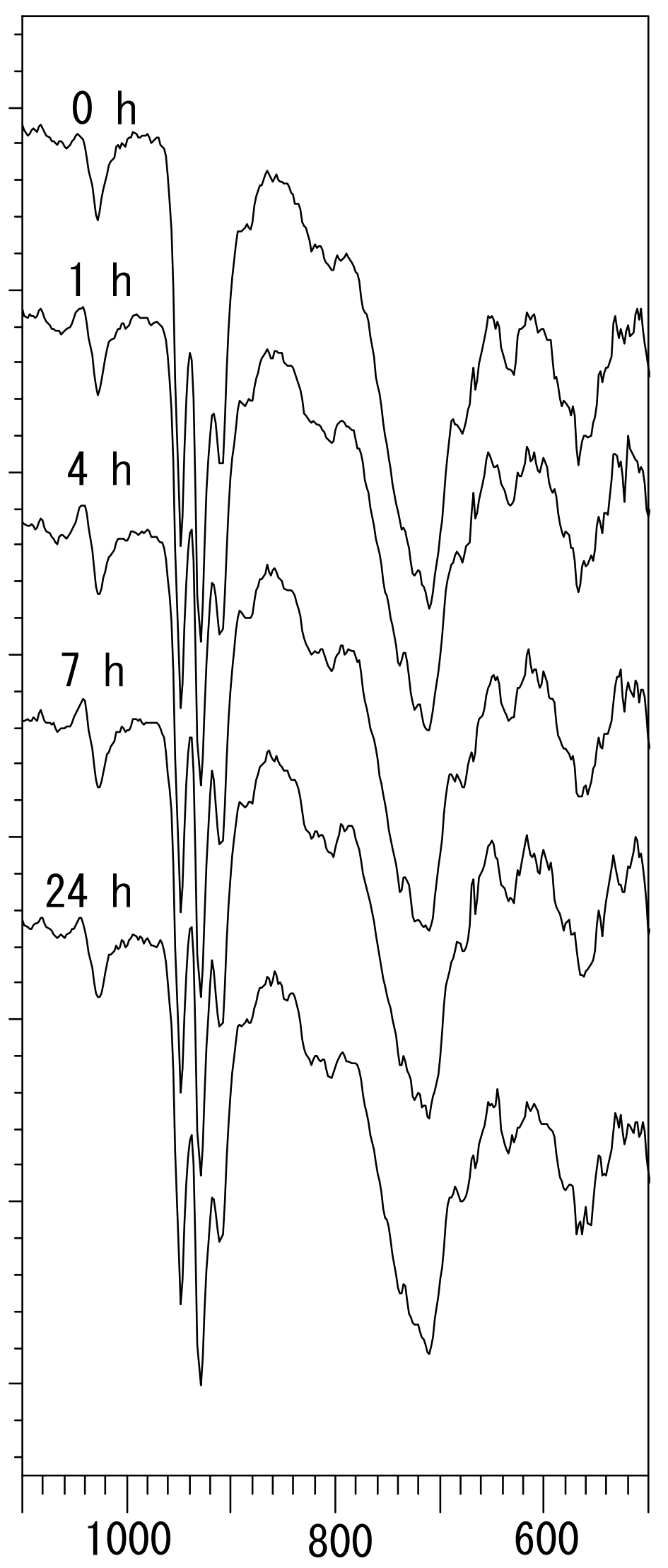

wave number $/ \mathrm{cm}^{-1}$ 
Figure S4. IR spectra of $\mathrm{TBA}_{4}\left[\mathrm{IMo}_{9} \mathrm{O}_{32}(\mathrm{OH})\left(\mathrm{OH}_{2}\right)_{3}\right] . \mathrm{H}_{2} \mathrm{O}$ in $\mathrm{MeCN}$.

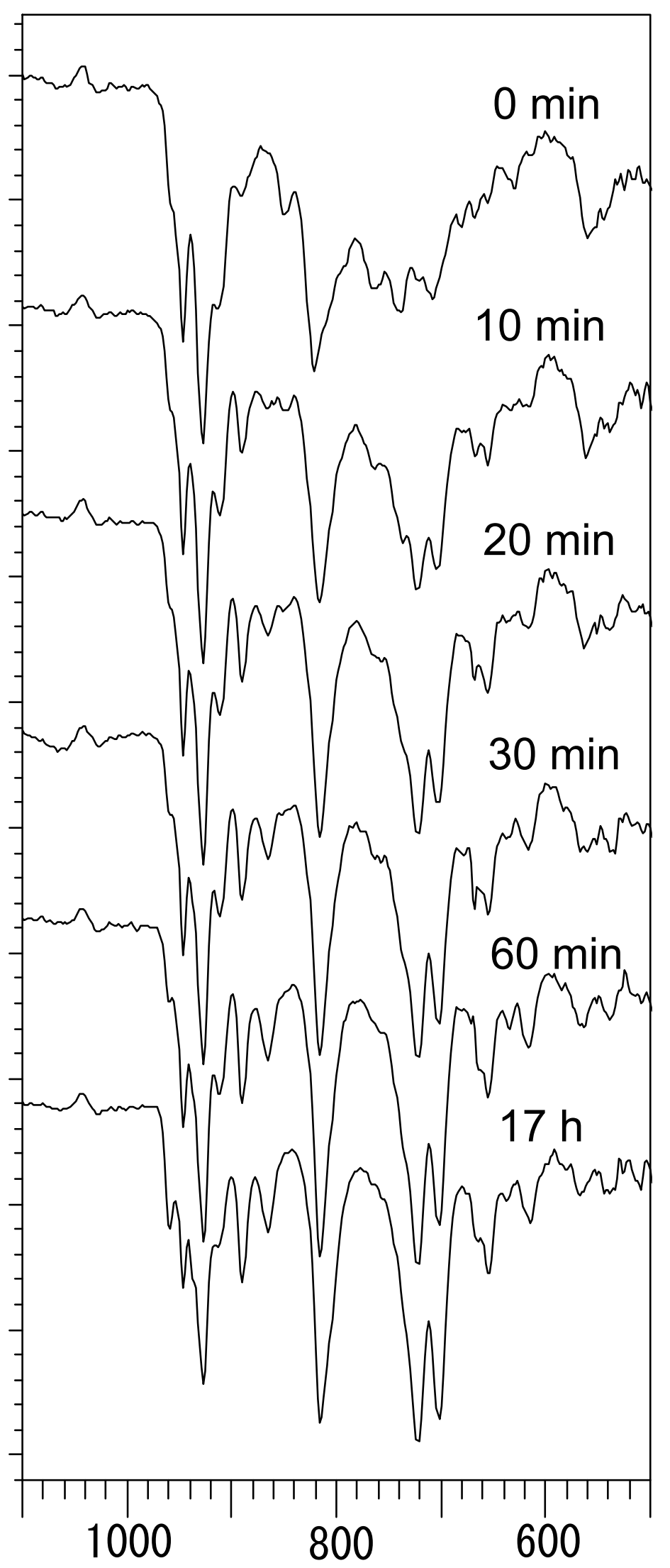

wave number $/ \mathrm{cm}^{-1}$ 
Figure S5. IR spectra of $\mathrm{TBA}_{4}\left[\mathrm{IMo}_{9} \mathrm{O}_{32}(\mathrm{OH})\left(\mathrm{OH}_{2}\right)_{3}\right] \cdot \mathrm{H}_{2} \mathrm{O}$ in wet $\mathrm{MeCN}$.

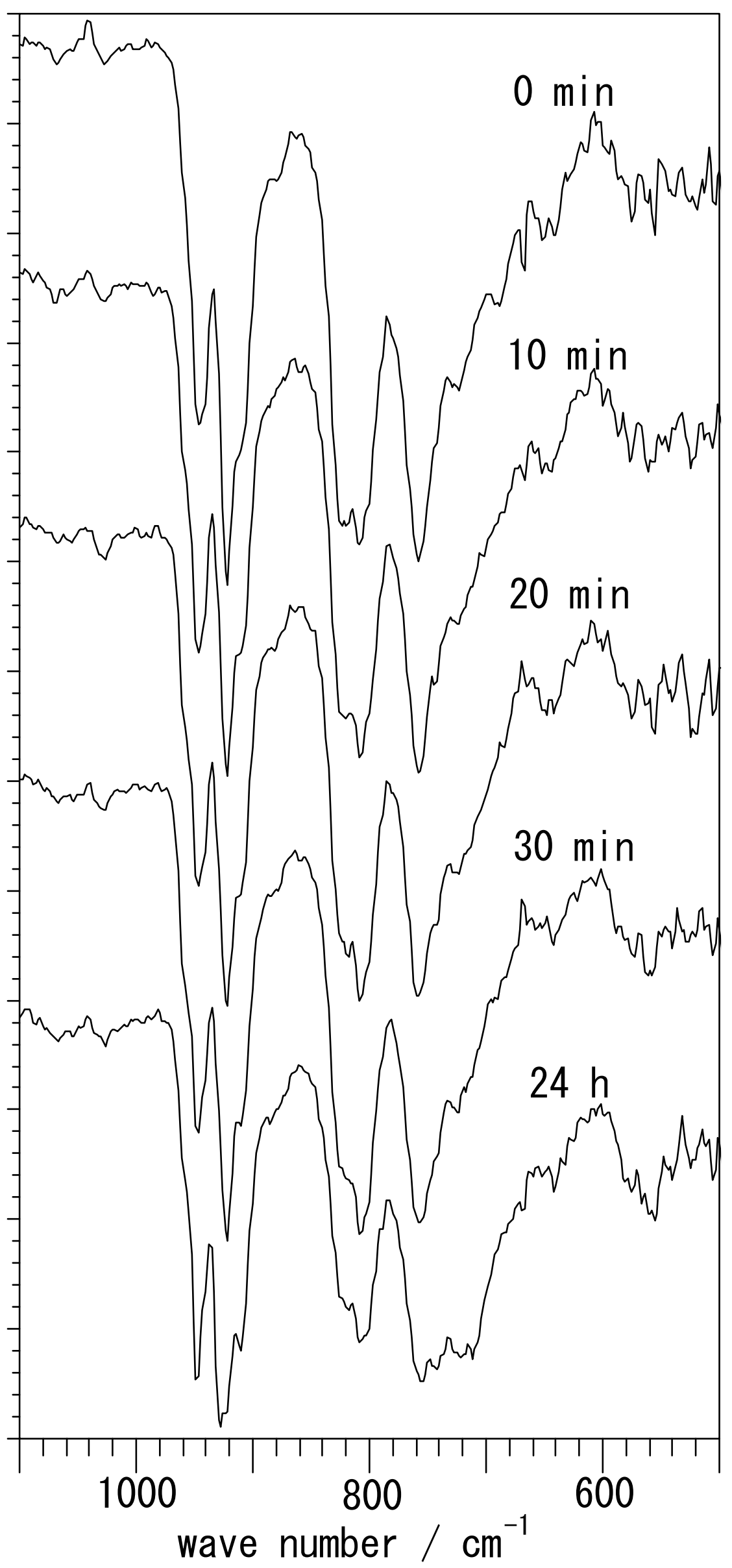


Figure S6. IR spectra of TBA6[(IMo7 $\left.\left.\mathrm{O}_{26}\right)_{2}\right]$ in Nujol mull (top) and in $\mathrm{MeCN}$ (bottom).

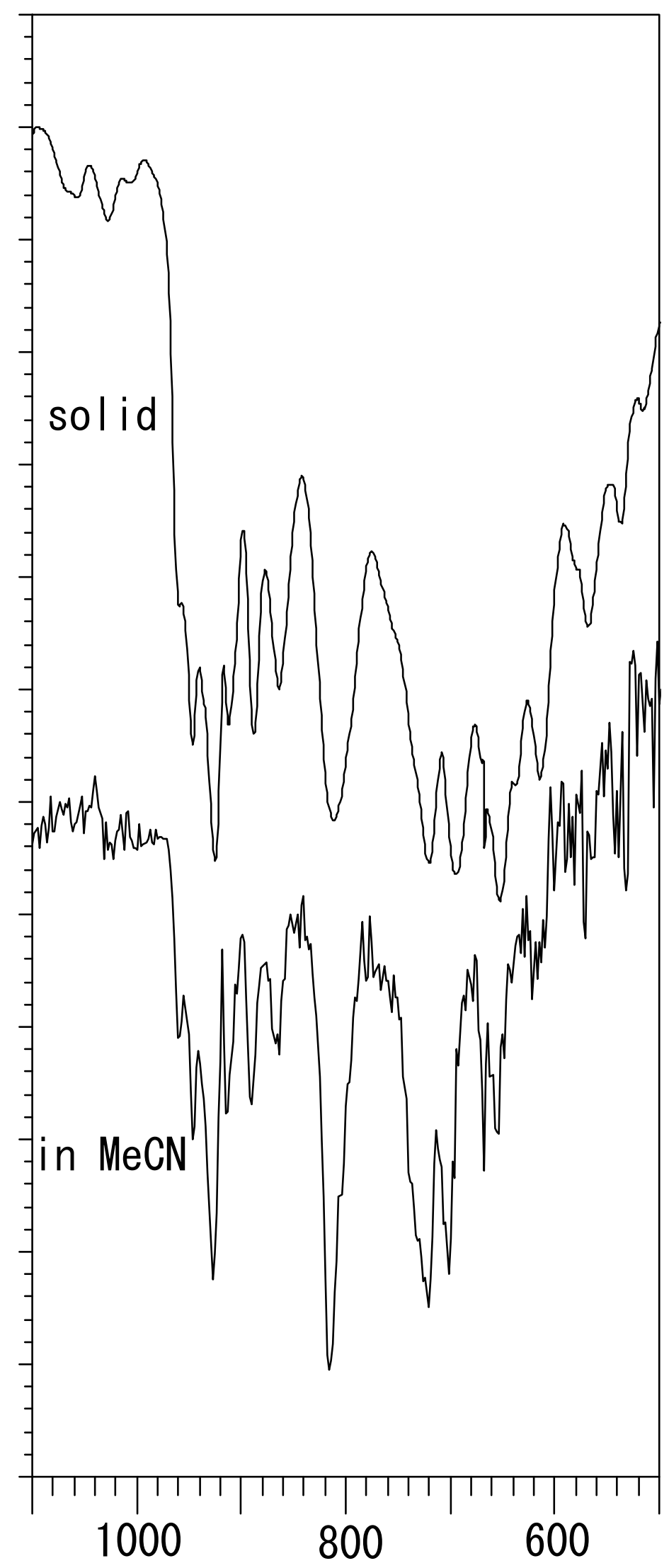

wave number $/ \mathrm{cm}^{-1}$ 